\title{
CSSR2019
}

6th International Conference on Science \& Social Research 2019 https://cssr.uitm.edu.my/2019/

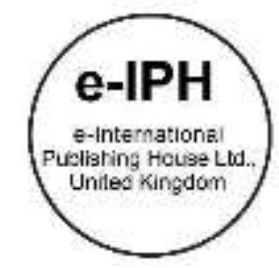

\section{The Application of Continuous Improvement (Cl) Methodology in Small-Scale (SME) Jewellery / Gold Fabricators \& Refiners toward Efficient Work Process in Waste Management.}

\author{
Saadiah Kaspin, Hanif Khairi, Oskar Hasdinor Hassan \\ Faculty of Art \& Design, Universiti Teknologi MARA (UiTM) 40450 Shah Alam, Selangor Darul Ehsan, Malaysia. \\ saadiahk@uitm.edu.my1hanif@salam.uitm.edu.my² oskar@uitm.edu.my³ \\ Tel of 1st Author: +603-5521 1471
}

\begin{abstract}
This paper presents the rationale of the continuous improvement $(\mathrm{Cl})$ system to be applied for the small-scale jewellery industry in the state of Kelantan State of Malaysia. The manufacturer's inefficiency during the fabrication process directly contributes to the potentially lost gold in scrap (waste) form that would eventually affect the producer's profit margin and may lead to a compromised quality of end products. Hence, the adoption of appropriate quality management applications and good practices are key to enhance business and operational efficiency towards sustainability of gold scrap and waste handling that may lead to potential economic loss.
\end{abstract}

Keywords: Sustainability; gold waste; continuous improvement (Cl); jewellery industry

eISSN: 2398-4287@ 2021. The Authors. Published for AMER ABRA cE-Bs by e-International Publishing House, Ltd., UK. This is an open access article under the CC BYNCND license (http://creativecommons.org/licenses/by-nc-nd/4.0). Peer-review under responsibility of AMER (Association of Malaysian Environment-Behaviour Researchers), ABRA (Association of Behavioural Researchers on Asians/Africans/Arabians) and cE-Bs (Centre for Environment-Behaviour Studies), Faculty of Architecture, Planning \& Surveying, Universiti Teknologi MARA, Malaysia.

DOI: https://doi.org/10.21834/ebpj.v6iSI4.2899

\subsection{Introduction}

The main purpose of this paper is to review the significance of Continuous Improvement $(\mathrm{Cl})$ applications in the gold and jewellery manufacturing process for medium and small-scale (SMEs) particularly the microenterprises jewellery industry in Kelantan. The spirit of review is in line with our Prime Minister Dr. Mahathir Mohammad's message to spur sustainable and equitable economic growth in SMEs themed 'A Connected World: Digitalizing SMEs' (SMEs Annual Report 2017/2018, (National SME Development Corporation (NSDC), 2018). The theme synchronized with SMEs Master Plan 2012-2020 as a 'game-changer in increasing the contributions of SMEs to the economy (Hirnissa Mohd et al; 2018). International Organization Standard (2015), defined quality management as a "principle" that is a basic belief, theory, or rule that has a major influence on how something is done.

"Quality management principles" are a set of fundamental beliefs, norms, rules, and values that are accepted as true and can be used as a basis for quality management. These principles also can be used as a foundation to guide an organization's performance improvement. They were developed and updated by international experts of ISO/TC 176, which is responsible for developing and maintaining ISO's quality management standards. The seven quality management principles are Customer Focus, Leadership, Engagement of People, Process Approach, Improvement, Evidence-Based Decision Making and Relationship Management. In Japan, they are propagating on Kaizen (Kai - do change, Zen - well) philosophy in both management and everyday life.

eISSN: 2398-4287@ 2021. The Authors. Published for AMER ABRA CE-Bs by e-International Publishing House, Ltd., UK. This is an open access article under the CC BYNCND license (http://creativecommons.org/licenses/by-nc-nd/4.0/). Peer-review under responsibility of AMER (Association of Malaysian Environment-Behaviour Researchers), ABRA (Association of Behavioural Researchers on Asians/Africans/Arabians) and cE-Bs (Centre for Environment-Behaviour Studies), Faculty of Architecture, Planning \& Surveying, Universiti Teknologi MARA, Malaysia.

DOI: https://doi.org/10.21834/ebpj.v6iSI4.2899 
This philosophy is translated in the west as ongoing, continuous improvement (Cl) (Singh Jagdeep, Singh Harwinder,2015). The phrase "Cl" is associated with a variety of organizational developments including the adoption of "lean manufacturing" techniques, total quality management (TQM) in each employee involvement program, customer service initiatives, and waste reduction campaign. Singh Jagdeep and Singh Harwinder mentioned that the principle of $\mathrm{Cl}$ is to improve the performance to product quality, services, and process to meet customer satisfaction. The data obtained from the literature has indicated that the problems relating to current practices in the small-scale jewellery industry include the potential of losing the weight of the gold. (Raw Peter, 2000), (C Corti, 2002) and gold quality issues (K.Saadiah, 2013).

To summarize, 6 key major factors have been identified as the prime challenges faced by the existing SME and small-scale fabrication outfit. The notable findings are the condition of the premises, type of fabrication process, non-updated handling procedures, condition of tools and equipment, management attitude, non-systematic and non-safe procedures in handling waste \& chemical reactions. The fabricators are perceived as treating the process with low tolerable standards of ignorance in addressing the stated prime challenges and prevalent issues that may affect the business operations and growth. Of recent, the external threat and disruption to business due to the rapid advancement of IR4.0 technology and digitalization are beginning to impact the business operations. Based on 3Q 2017 SME Survey, that evaluates the status of awareness and readiness of SMEs towards IR 4.0, revealed that $62.1 \%$ of the respondent is facing problems on insufficient knowledge and skills of employees. The survey result indicates that it is timely for the jewellery fabricators to start preparing their tech-based skills and platform to moves quickly and by avoiding being left out in the competition,

Despite current issues with process inefficiency. the SMEs need to prepare themselves with the required technological knowledge to stay relevant in the market (Nur Raihana Mohd Salim et al.; 2017). Hence, as the pressure from internal and external factors are now more prevalent than before, it is timely for the SMEs and small-scale outfit to start looking the best model to strengthen their internal processes with the right fundamentals by adopting the right quality management practices with the focus to produce a consistent quality of product and boost market presence.

With that in mind, the review on the Cl implementation through Total Quality Management (TQM) philosophy is becoming more significant to ensure process competitiveness, solid product, operational efficiency, and risk mitigations through the development of holistic policy and standard operating procedures (SOP) for small scale and micro enterprises companies. To ensure the right framing and gaps identification in each process, Value Stream Mapping (VSM) was used to plot the end-to-end value chain processes that involve in the jewellery making waste handling from the small-scale fabrication refiners in the Kelantan state.

This is to encapsulate the importance of this research objective that aims to identify the right continuous improvement $(\mathrm{Cl})$ methodology in managing and handling the gold waste yield during the crafting process in the small-scale gold refiners in the Kelantan state. Secondly, to ensure the development of complete documentation of standard operating procedures (SOP) and operational guidelines to address the gaps derived from the review of processes such as waste processing cycle time, frequency, and waste handling checklist. In Malaysia, a few government agencies play a pivotal role in the policy establishment and monitoring of the environmental system in Malaysia to be in line with the Sustainable Development Goals (SDGs) propagated by the United Nations, such as the Department of Environment Ministry of Energy, Science, Technology, Environment \& Climate Change (DOE), Department of Occupational Safety and Health (DOSH), Malaysia Productivity Corporation (MPC), The Department of Statistics Malaysia (DOSM) and The National SME Development Council (NSDC).

In line with the spirit of achieving sustainable goals, this review also will focus on how to address the possible environmental issues in the form of waste handling through recycling and process improvement. The research data has diligently worked on the plotted processes and map through the value chain analysis to understand the real root cause and ways to address them. Small-scale refiner's fabrication process will be tabulated, analyze and benchmark to ensure such waste handling and management are carried out prudently and diligently through the adoption of the right quality and process improvement methodology. The researcher believes that the outcome of this review would be significant and directly benefitting the small-scale players by bringing the processes to the next level. Nevertheless, the scope and focus of the quality in this paper would be focus merely on the development of the right SOPs based on the deployed quality and continuous improvement method, whilst acknowledging further limitations may cause by the other key factors such as human errors and skills. From the overall reviews, more than $60 \%$ significant gaps were contributed by the irregular practices, improper planning, and absence of operating procedures. Thus, that makes the intended SOPs important by focusing on the way and mean to standardize the processes so that they can be more transparent, clearer, consistent and closing the key gaps in the fabrication processes.

\subsection{Literature Review}

2.1 The application of Continuous Improvement (Cl) and Sustainable Development Goal (SDGs) of SMEs in Malaysia.

The goals of such a continuous improvement $(\mathrm{Cl})$ system focus on producing the best quality of products at an efficient cost and being able to fulfil the customer just in time' and 'just in need' requirements. The right $\mathrm{Cl}$ will improve the back-end processes efficiently by enhancing the production of quality products, zero downtime, low defect ratio, and effective handling of production flow by eliminating wastes and optimized workforce (Federica Costa; et al. 2018). Federica also mentioned the $\mathrm{Cl}$ is a combination of synergetic and dynamic practices that allows such as smooth integration of both technical and human aspects in both production and handling of materials and products.

It's worthy of highlighting that Malaysia's undivided commitment to support the Sustainable Development Goals (SDGs) mooted by the United Nations General Assembly in New York in September 2015 to embrace the improvement of many systems for process sustainability is in line with the spirit of this research. In summary, SDGs aims to support and implement the World's 2030 Agenda in 17 goals which prioritize poverty, hunger and food security, health, quality education, gender equality, water and clean sanitation, economic growth and urban city, responsible production and consumption, climate change and biodiversity as key pillars. 
SDGs are a highly ambitious plan that combines a seamless focus for people, the planet, prosperity, and partnership. In line with the undivided commitments, The Department of Statistics Malaysia (DOSM) has been appointed as a focal point in the coordination of the development of SDG indicators that focus on Malaysia's social, environmental, and economic development. Dato' Sri Dr. Mohd Uzir Mahidin, Chief Statistician of Malaysia in his report finding titled 'The Initial Assessment of The Sustainable Development Goals Indicators for Malaysia 2018' analyzed that SDGs in Malaysia would integrate and balances the 3 key dimensions of sustainable development; social, environmental and economic with 5 focus areas; people, planet, prosperity, peace, and partnership. These findings were then referred to and guided by the government agencies, private sectors, academicians, and individuals for comprehensive SDGs implementation.

Alluding to the overall sustainability agenda, Waste management has been identified as one of the main concerns in the SDGs agenda that should be prioritized coherently with the context of environmental sustainability in Malaysia. Malaysia was targeting to achieve $30 \%$ of total solid and scheduled waste recycling in 2021 as compared to the current $5 \%$ level (Utusan Malaysia, 2009). Acknowledging the big gaps in terms of ratio, a persistent and consistent approach is needed by every industry stakeholder to ensure we achieve the aspired goal. This is no exception to the Gold refining industry. Therefore, in line with the concept of $4 R$ that focus on the elements of reduction, reuse, recycling, and recovery, it is likely an opportunity for the small-scale and SME players to take advantage by regulating and improvising the process to achieve higher efficiency and build business growth for long term sustainability.

To recap the speech by the Former Prime Minister, Dato' Sri Mohd Najib bin Tun Haji Abdul Razak speech a decade ago during Green Forum 2010 at Putrajaya, encouraged local research center and industries alike to look for global solutions by partnering with strong foreign green institutions, be it from the universities or multinational companies since environmental issues are global. He believed that the green technologies able to provide environmental sustainability with a minimum cost of implementation and more accessible to the man on the street, research, development, and commercialization must focus on reducing the cost of purchasing smart devices and technologies so that all levels of the society can contribute towards environmental sustainability. The support indicates a clear government's seriousness and commitment towards making waste management a key driver for environmental and business sustainability.

Also, worthy of highlighting that Malaysia Productivity Corporation (MPC), a Malaysian Agency under the Ministry of International Trade and Industry (MITI), has also been aggressively supporting any effort towards sustainability since the 2000s and involved with various benchmarking and sharing of best practices to improve organization's productivity standards. MPC has worked with multiple stakeholders to conduct insightful research on sustainable development initiatives that were benchmarked based on top industry organizations to understand and gauge their level of green practices in manufacturing and production. Quoted in their report findings titled 'Sustainable Development Initiatives in Malaysia' (2010), they defined sustainable development as inculcating the process of maintaining human needs while preserving the environment for future generations. The MPC has encouraged Sustainable development to be pursued extensively to have a preferable future that includes a cleaner environment, a sustained level of economic development without excessive waste and pollution, and the protection of natural resources and biodiversity. MPC aims can be further achieved by developing a sense of citizenship in the sustainable development process through the delivery of quality education, a reappraisal of our core values systems, and the empowerment of communities to make their own decisions on the future that they want to see - both for ourselves and our children.

To narrow down the sustainability agenda in a more focused waste management context, Nadi Behzad et al.; 2011; have categorized the benefits of waste management into two-fold. Firstly, recycling cuts down the need for disposal capacity and lowers emissions from landfills as well as reduces litter. Secondly, the use of recycled materials in industrial reduces energy use and emission; lessens the impact when raw material is extracted or manufactured and conserves raw materials. He suggested correlating the implementation of integrated solid waste management with regard to the environmental needs to achieve environmental sustainability in Malaysia. To reduce pollution and environmental degradation, the approach between economy and technology is very important to make sure the process of waste management is more efficient and avoids potential problems with regards to public health and the environment. With this focused context, adopting the concept of sustainability to small-scale gold fabricators and refiners could be pivotal steps in uplifting their business processes and address the legacy and norms that have been lingering with the process for decades. It is not easy as the selection of process enhancement application whilst ensuring quality end product at the most efficient cost is the paradox that needs to be addressed with clarity, transparency, and control.

\subsection{The Definitions and Contribution of SMEs Industry in Malaysia}

The New Definitions of Small Scale and Medium Enterprises (SMEs) for Malaysia was announced during 14th The National SME Development Council (NSDC) meeting in July 2013 in Putrajaya. The new definitions are expected to improve the transformation to a highincome nation through the initiatives under the SMEs Master Plan. The clarifications for the new SMEs definition are as follows.

Table 1: New Classification of SMEs

\begin{tabular}{|c|c|c|c|}
\hline SMEs Category & Micro & Small & Medium \\
\hline Manufacturing & $\begin{array}{l}\text { Sales turnover of less than RM } \\
300,000 \text { OR employees of less } \\
\text { than } 5\end{array}$ & $\begin{array}{l}\text { Sales turnover of less than RM } \\
300,000 \text { to less than RM15mil } \\
\text { OR employees from } 5 \text { to less } \\
\text { than } 5\end{array}$ & $\begin{array}{l}\text { Sales turnover from RM15 mil not } \\
\text { exceeding } 50 \text { mil OR employees from } 75 \\
\text { to not exceeding } 200 \text { than } 5\end{array}$ \\
\hline Service & $\begin{array}{l}\text { Sales turnover of less than RM } \\
300,000 \text { OR employees of less } \\
\text { than } 5\end{array}$ & $\begin{array}{l}\text { Sales turnover of less than RM } \\
300,000 \text { to less than RM3mil } \\
\text { OR employees from } 5 \text { to less } \\
\text { than } 30\end{array}$ & $\begin{array}{l}\text { Sales turnover from RM3 mil not } \\
\text { exceeding } 50 \text { mil OR employees from } 30 \\
\text { to not exceeding } 5\end{array}$ \\
\hline
\end{tabular}

Source: National SME Development Council (NSDC), 2013 
The importance of SME's performance and contribution to Malaysia's economic growth cannot be denied (Mitra Madanchian, et al., 2015) and undebatable (Tairudin Yusoff, et al.; 2018). Malaysia Prime Minister, Dr. Mahathir Bin Mohamad in his message stated that SMEs contribute more than one-third of our economy. In 2017, SMEs contributed RM435.1 billion to the economy with a higher Gross Domestic Product (GDP) of $7.2 \%$ against $5.2 \%$ in 2016. However, for our SMEs to be on par with those in the advanced economies much more needs to be done. PM also claimed that one of the new Government's pledges is to spur sustainable and equitable economic growth towards better-shared prosperity and to achieve this, is to develop and empower the SMEs (National SME Development Council (NSDC), 2018).

The government is aware that the key problems faced by SMEs in maintaining their business toward globalization are ranging from financial constraints to management skills, marketing issues, and operational inefficiency (Nurulhasanah Abdul Rahman et al, 2016). Instead of that (Abu Bakar Sedek Abdul Jamak et al; 2011) identified that the number of the business advisory services sponsored by the government is not fully utilized, poor formulation, implementation, evaluation, and control of the support program in SMEs management. To support the SMEs in facing the problems and issues, the government has launched various programs, incentive and funds have been launched especially for small and microenterprise companies for their business development to improvise the capabilities of SMEs and enhance the internationalization of their products and services, despite lack of success stories.

A survey by Census 2016 reported that $98.5 \%$ of Malaysia's total business establishments are from SMEs. In terms of size, the microenterprise industry represents $76.5 \%$ of SMEs with 693,670 companies followed by a small scale industry with $21.2 \%$ and 192,783 establishments (Department of Statistic, Malaysia, 2017). SMEs played a role in fostering growth, employment, and income in the past and can be considered as the backbone of Malaysia's industrial development (Hirnissa Mohd et al; 2018). Malaysian SMEs breakdown by sector shows that $89.2 \%$ is from the service sector, followed by manufacturing $5.3 \%$ and construction $4.3 \%$. Kelantan State was a higher number of SMEs industry distribution on the East Coast with 46,618 companies followed by Pahang 37,573 and Terengganu 29,324 companies. Kelantan's performance in the manufacturing sector in 2017 was higher in Malaysia with 9.1\% of Gross Domestic Product (GDP) (Press Release, Department of Statistics (DOSM), 2018). The manufacturing sector is defined as the physical or chemical transformation of material or components into a new product (Bank Negara Malaysia Circulation (BNM/RH/CIR 028-1, (NSDC), 2013).

\subsection{The Significant of Continuous Improvement $(\mathrm{Cl})$ System in Jewellery Industry in Kelantan}

This research limits and focus merely on Kelantan's jeweller industry players as it is well-known as 'Kelantan Gold'. It was indeed one of the most popular jewellery buyer destinations due to its unique traditional design with affordable and reasonable cost and prices. Their popularity cut across other states in Malaysia and has the prowess to attract potential local buyers, tourists, and gold lovers. Indeed, this popularity status is contributed by the fact that Kelantan has the most renowned state for small-scale and microenterprise gold jewellery making as compared to other states in Malaysia like Terengganu and Pahang. Based on the total SME industry population on the East Coast, Kelantan was positioned as the second larger gold producer with 1,006.661 grams of gold with 5 gold mines. Therefore, the performance of SMEs jewellery business in Kelantan should be synchronized with the fact of the number of gold produced by the state and the higher number of Gross Domestic Product (GDP) in the manufacturing sector in Malaysia. Hence, priority should be taken regarding improving and enhancing the performance of the SMEs jewellery industry in Kelantan. The other state and gold producing tabulated as below;

Table 2: Gold Produced in 2016

\begin{tabular}{|l|l|c|}
\hline State & Gram & Gold Mine \\
\hline Pahang & $1,220,648$ & 5 \\
\hline Kelantan & $1,006,661$ & 5 \\
\hline Terengganu & 21,682 & 2 \\
\hline Total & $2,248,990$ & 12 \\
\hline \multicolumn{2}{|c|}{ Source: Department of Mineral and Geosciences Malaysia (JMG) }
\end{tabular}

Regarding New Definitions of Small Scale and Medium Enterprises (SMEs) for Malaysia, most of the jewellery industry in Kelantan can be categorized under the small scale and microenterprises (MPEs) companies. The jewellery Industry is classified as the manufacturing sector in New Circulation on Definitions of Small and Medium Scale Enterprises (SMEs). The jeweller manufacturers do not only fabricate the jewellery product, but they also offer other relevant services such as trade in gold, product repair, product designing, gold specifications identification, refining gold, and others.

As discussed, the problem is facing the small scale and MPEs in implementing the quality and best practices in managing the business is quite challenging due to different priorities and focus by the existing management team. (K Saadiah and N Mohamad, 2015) have analyzed that most of Kelantan's jewelers are still using the traditional techniques and tools in their fabricating process. The current techniques in jewellery fabrication processes such as filing, piercing, grinding and others will cause a loss of gold. They also maintain the tradition, tools, and techniques in fabricating products that had been inherited from families. Based on the preliminary survey, the manufacturer has identified both techniques and design complexity are the main cause of gold wastages as they have limited time to produce. To cater to the demand that mostly required them to produce different complexities such as master antique jewellery with some aesthetic value; these designs need to be crafted manually and, therefore, higher probabilities for higher waste.

Some other norms techniques applied by the small-scale jewellery manufacturer is a lost wax casting. Even though the number of fabricators and refiners practising this lost wax casting technique in Kelantan is not that high due to complexity in terms of processes and cost, it does allow them to produce a high volume of products at one time. Imagining the number of gold waste particles produced during this kind of fabrication process, and by nature, the waste is light, and as dust on the work surfaces, pipes and operating clothes, and these 
are hard to retrieve. With this dust are circulated in the air, it is has a direct effect on the hazard conditions of the craftsmen's table/ workshop with concern on the air pollution that may affect the health of the employee. The traditional design and old process methodology do contribute to the higher potential of gold wastage as the nature of the old fabrication process is tedious and complex as compared to contemporary design. In Kelantan, most fabricators and refiners would prefer the traditional method in their fabrication process due to their limitations in terms of the latest processes, technology, and skills. Through my observation and records, the existing methodology produces a significant ratio of gold scrap ranging from 1 gram to 2 grams on average for each fabrication process.

Thus, due to inefficient waste management and limitations during the process, the potential loss from the inconsistent and inefficient fabrications and gold wastage handling will impact the refiners in the long run economically. In some cases, the craftsmen refiners will collate and re-cycle internally gold waste into new products that may compromise the health and safety of the employee. The refining method applied by small-scale refiners is considered hazardous and can cause potential health hazards due to the unsystematic and unsafe procedures (S.Kaspin, 2013). (Raw Peter, 2000) , (S. Kaspin, 2013) and (K Saadiah and N Mohamad, 2015) The researcher stated that factors that lead to gold losses in a small or large amount especially in small scale and enterprise jewellery industry in (Table 3) and (Table 4) below;

Table 3: Factors of the Gold Losses (1)

\begin{tabular}{|l|l|}
\hline Factors & Reason \\
\hline Poor Condition and Design of the Premises & $\begin{array}{l}\text { To collect waste from jewellery fabrication processes such as dust, filing, } \\
\text { premises are required to have a routine schedule and proper facilities. }\end{array}$ \\
\hline The type of manufacture & $\begin{array}{l}\text { The number of gold losses is higher if the manufacturers produced products manually as compared } \\
\text { to the mass production scale produced by machines. }\end{array}$ \\
\hline Type of Jewelry Design & $\begin{array}{l}\text { The traditional design is very complicated to fabricate and contributes a higher amount of gold losses } \\
\text { compared to contemporary and modern design, which is more simple and plain. }\end{array}$ \\
\hline The condition of Machinery or equipment & $\begin{array}{l}\text { The poor maintenance and aging machines will contribute more unexpected losses to the } \\
\text { manufacturers. }\end{array}$ \\
\hline The management attitude & $\begin{array}{l}\text { The manufacturers must be responsible for the higher standard operating process of housekeeping } \\
\text { practices systematically managed to avoid the unnoticed gold losses during the fabrication process. }\end{array}$ \\
\hline \multicolumn{1}{|c|}{ Sources: Raw Peter, 2000 }
\end{tabular}

Table 4: Factors of the Gold Losses (2)

\begin{tabular}{ll}
\hline Factors & Reason \\
\hline $\begin{array}{l}\text { Unsystematic and unsafety procedures in } \\
\text { handling waste }\end{array}$ & $\begin{array}{l}\text { The process has caused environmental pollution due to improper handling of the chemical, } \\
\text { and the purity of gold recovered doesn't meet the standard. }\end{array}$
\end{tabular}

Source: S Kaspin; 2013, K Saadiah and N Mohamad; 2015

\subsection{Methodology}

Value Stream Mapping (VSM) is adopted to map the material and information flows required to coordinate the activities performed by manufacturers, suppliers, and distributors to deliver products to customers. Meanwhile, the process is known as any activity that changes or transforms some input(s) to create output. VCM is managed to focus on how activities on every step and operation can be connected and generate an analysis of the process to be more practices and understandable (Jostein Langstrand,2016). In this study, the mapping processor flowchart is a basic and primary tool towards process improvement and focuses on workstream processes which are in this case, refers to gold waste management. There is two divided group process in VSM; Value Adding (VA) and Non-Value Adding (NVA) (Thomas Rohac, Matin Januska, 2015). NVA is a process that we need to be eliminated while VA is needed and significant process. SVM will help the manufacturer to strategize, plan the decision-making and improvement based on the clue that resulted from the map itself. Figure 1. shows how the process improvement flowchart or map in work processes is strategized for future processes.

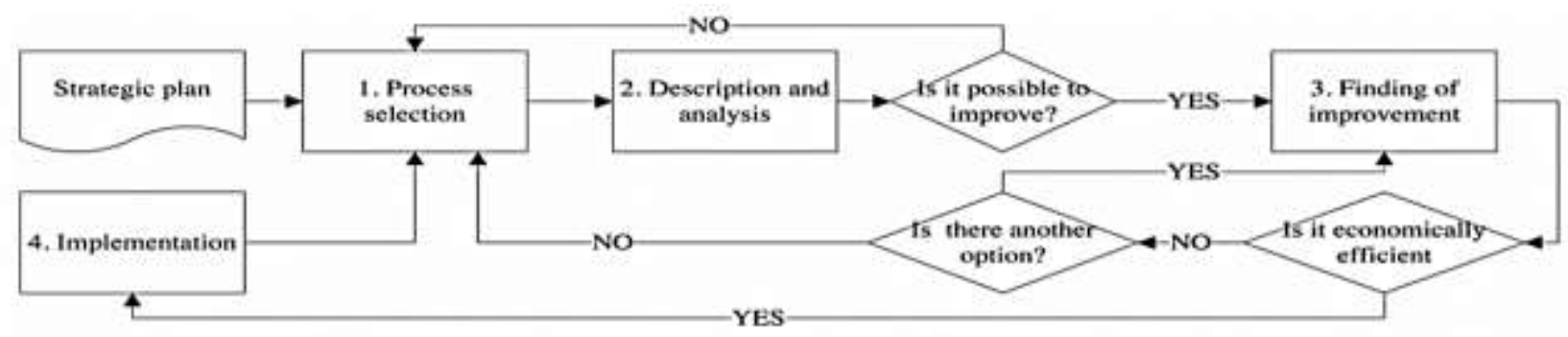

Fig.1. Process improvement procedure. (Thomas Rohac, Matin Januska, 2015)

\subsection{Findings}


The current waste management of VSM (Fig. 3) was implemented by the refiners shows the types of suppliers and customers involved in the jewellery industry in Kelantan. The work processes were divided into four major processes, which are lower grade gold, melting for gold grain, refining, and melting for gold bullion. Collecting schedules from suppliers are inconsistent frequency as well as a delivery schedule to the customers. Process time for all processes is 7.5 hours due to the longest time to extract the pure silver from silver chloride, which is almost 6 hours. The findings also clearly indicated an inconsistent tracking and records of the waste materials handling and irregular frequency schedule from both supplier and delivery schedule. To add, based on interviews and discussion feedback, we also found that there is no proper SOP and guidelines for inventory control for both material handling and processing leads to a longer waiting period.

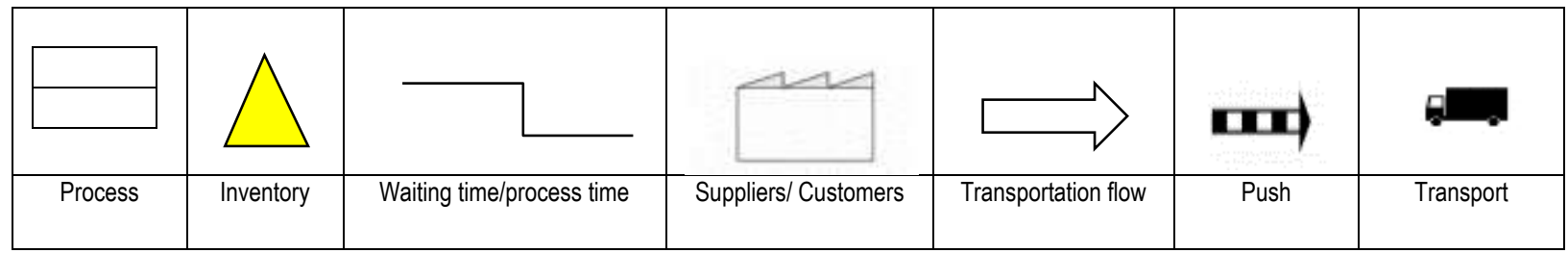

Figure 2. The icon used in the current VSM of the gold waste management process.

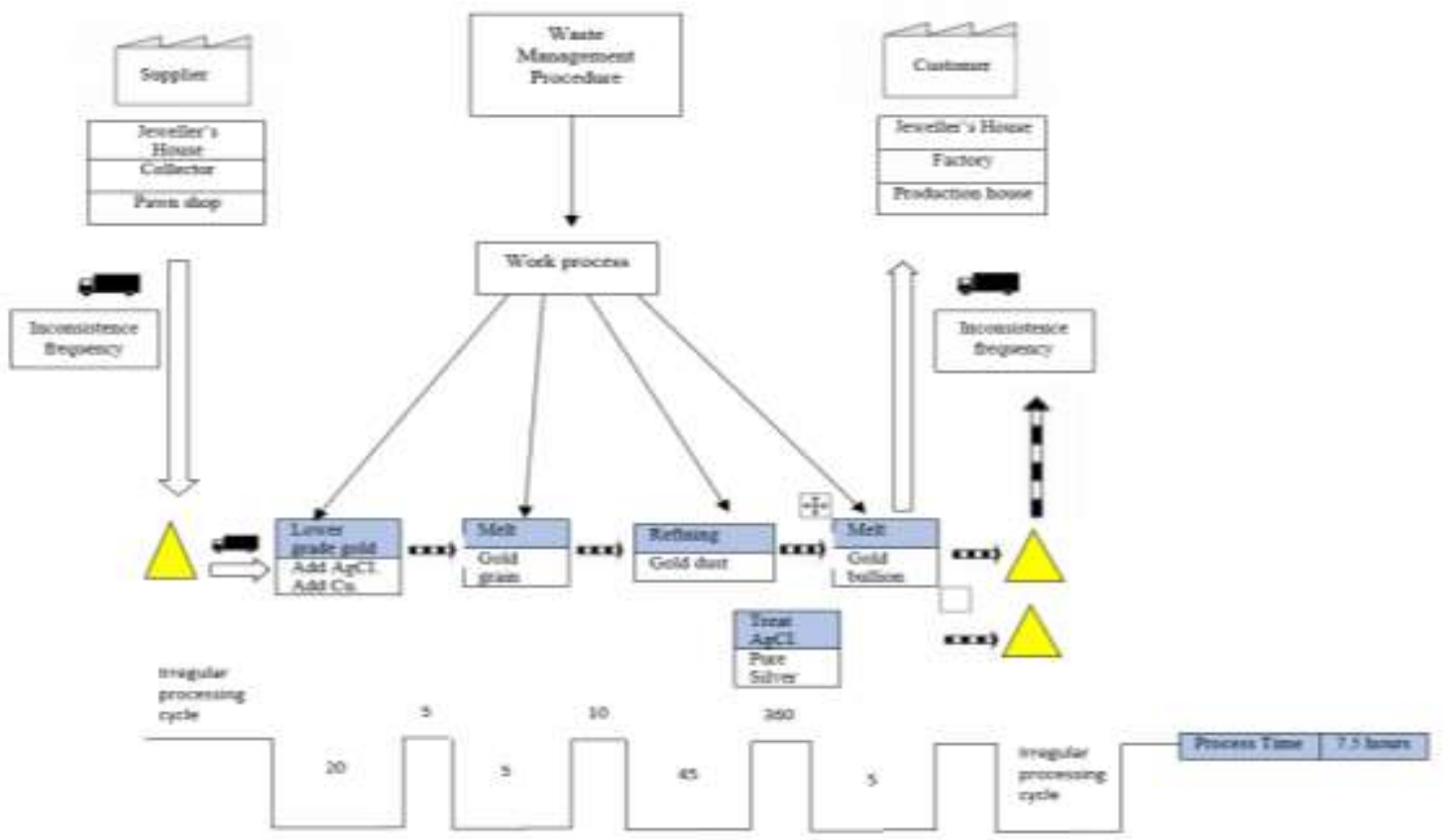

Figure 3. Current Value Stream Map

\subsection{Discussion}

As discussed earlier, the contribution of SMEs, including microenterprises, to economic development in Malaysia is key as sources of growth and establishing the substructure for the fast economic growth and development of the country (Mitra Madanchian et al., 2015). As to ensure the objectives in sustaining the growth of SMEs Master Plan 2012- 2020, a clearer roadmap has been laid out by the government in providing incentives, schemes, and programs such as Microenterprises Programmes (MPEs) for a home-based business. However, (Tairuddin Yusoff et al., 2018) have claimed that the attention to achieve the sustainable growth of SMEs, including microenterprises, has not been given emphasized due to the difficulties to assist practitioners and policymakers alike to equip with relevant strategies and plans to sustain the growth of the SMEs. Thus, to balance the two emerging priorities, it is high importance for the key stakeholder to ensure a clear roadmap and project capstone that focus on management quality products and building resources (skills and capabilities) are pivotal for the SMEs to thrive in this challenging business landscape.

Focus to embark a comprehensive yet logical, continuous improvement $(\mathrm{Cl})$ initiatives for the SMEs in the jewellery fabrication and refining industry with the aims to improve operational efficiency, better internal processes for both production and management systems, waste management handling, and quality product to bring the business towards sustainability. It is key to highlight that the process gaps can be addressed with the right continuous improvement methods that enhance quality and tighten the process to reduce wastages and improve economic returns, i.e. adopting the right Total Quality Management (TQM) and Six Sigma approaches in managing the business will improve the handling of waste management process which literally will increase the business returns.

In the SMEs Master Plan, 2012-2020 has indicated that $42 \%$ of the SMEs that existed in 2000 failed to survive through 2005 , and statement supported by AmBank's Managing Director in his launching of the entrepreneurship challenge stated that almost $80 \%$ of SMEs do not survive the first three years (Tairuddin Yusoff et al., 2018). Mirroring the same context, the Jewellery industry in Kelantan (especially 
refiners and fabricators) will be facing more serious problems due to lagging in terms of technology, process, and quality products, added with a shortcoming in terms of leadership and skills.

The gaps are getting too big, and without proper continuation plans, the future for small-scale fabricators and refiners can be jeopardized, resulting in the loss of jobs and income. It's a complex problem to resolve, and getting it certified with good quality and continuous practices can be regarded as the key milestones before any actions towards automation and digitization can be materialized.

As discussed earlier, the production and scale and processes need to be enhanced to ensure better competitiveness and cost management that leads to better profit margin. The actions must be taken to overcome this problem to develop more opportunities for the small-scale refiners and fabricators to access wider and bigger markets in line with the borderless and globalized marketplace.

I would like to quote from a survey conducted in adapting the TQM in business resulted in only $16 \%$ of SMEs used ISO certification as an approach in their business, and the philosophy of TQM (Total Quality Management) is not used at all due to of lack of awareness of SMEs in quality consciousness, underutilization of capacity, lack of financial strength, non-availability of trained workers, lack of culture due to low industrial development and high interest on the loan are some of the common problem faced by SMEs (Kalpande et al.). He suggested a few plans to ensure the understanding of the quality management issues in business which are tabulated below;

Table 4: Total Quality Management issues in SMEs business.

\begin{tabular}{ll}
\hline Case & Suggestions \\
\hline Manager/ Entrepreneur & Education and training regarding the benefits and need for continuous improvement \\
Employees & Education \& training on various aspects like quality and its need, the importance of \\
& Cl, use of data, and understanding of processes. \\
Technology Adoption & $\begin{array}{l}\text { Development of competitiveness through the use of better technology, use of } \\
\text { improved equipment and testing facilities }\end{array}$ \\
\hline & Source: Kalpande et all.; 2010
\end{tabular}

Hence, based on the factual findings from the data literature and problem statement faced by the jewellery/gold refiners and fabricators in Kelantan, it is timely for the industry to be serious and start to adopt the right $\mathrm{Cl}$ initiatives system as part of the effort to enhance their fabrication process, maximizing their profits and enhance the workforce skill to be competitive and be sustainable in the long run. Continuous improvement $(\mathrm{Cl})$ system can be further applied with the context of Lean Six Sigma (LSS) that focuses on process efficiency and enhancement to uplift the standard and quality of the products as well as to ensure better management of waste from the fabrication process.

\subsection{Conclusion \& Recommendations}

In conclusion, $\mathrm{Cl}$ practices in the manufacturing process are pivotal and essential to ensure the sustainable growth of SMEs, especially amongst the microenterprise jeweller fabricator and manufacturing industry in Kelantan survives and sustainable. The implementation of Lean Six Sigma (LSS) as an initiative in the jewellery industry can be considered a crucial action plan to improve the work process, step up with a new approach, eliminate waste, remove access cost, reduce variation, and maximize customer experience through quality products. The process can be replicated and replicable to ensure consistency and better monitoring processes to produce a quality product.

The implementation of Lean Six Sigma (LSS) as one of the tools for $\mathrm{Cl}$ would be able to educate the workers and managers to follow the right process and procedures in handling the raw material, equipment, and machines. As part of driving process improvement through big data in line with industry 4.0 practices, manufacturers are encouraged to do a compilation as data references and assist them to identify the actual number of precious metals enters in the workshop and how many turns into finished jewellery. The quantity of gold waste from the benchwork or sent for refining will be important data to evaluate how much is being lost in the system. An appropriate plan, action, standard procedures, or system using Lean Six Sigma (LSS) is needed to be a new guideline for the manufacturers in handling the waste through sustainable management system to ensure the sustainability of their business growth towards being competitive and able to produce a high-quality product and services.

\section{Acknowledgement}

The authors are grateful for the support and cooperation obtained from local fabricators \& refiners, Jewellers House, and relevant Government Agencies during the data gathering process.

\section{References}

Tahir, H. M., Razak, N. A., \& Rentah, F. (2018, March). The contributions of small and medium enterprises (SME's) On Malaysian economic growth: A sectoral analysis. In International Conference on Kansei Engineering \& Emotion Research (pp. 704-711). Springer, Singapore.

RAW, P. M. (2000). Gold losses and control in gold jewellery manufacture. Gold Technology, 29, 17-24.

Kaspin, S. (2013, June). Small scale gold refining: Strengths and weaknesses. In 2013 International Conference on Technology, Informatics, Management, Engineering and Environment (pp. 32-36). IEEE.

Kaspin, S., \& Mohamad, N. (2015, July). Gold refining process and its impact on the environment. In Environmental Engineering and Computer Application-Proceedings of the International Conference on Environmental Engineering and Computer Application, ICEECA 2014 (pp. 19-22). CRC Press/Balkema. 
Sallem, N. R. M., Nasir, N. E. M., Nori, W. M. N. W. M., \& Kassim, C. K. H. C. K. (2017). Small and medium enterprises: Critical problems and possible solutions. International Business Management, 11(1), 47-52.

Madanchian, M., Hussein, N., Noordin, F., \& Taherdoost, H. (2015). The role of SMEs in economic development: A case study of Malaysia. International Journal of Academic Research in Management, 4(3), 77-84.

Rahman, N. A., Yaacob, Z., \& Radzi, R. M. (2016). The challenges among Malaysian SME: A theoretical perspective. World, 6(3), 124-132.

Abdul Jamak, A. B. S., Salleh, R., Sivapalan, S., \& Azrai, A. (2010). Entrepreneurial challenges confronting micro-enterprise of Malaysian Malays.

Thaker, M. T., \& Mohammed, M. O. (2013). The challenges of micro-enterprises in Malaysia and the prospect for integrated cash waqf microenterprise investment (ICWME-I model. Small and medium enterprises (SMEs) in selected Muslim countries.

Yusoff, T., Wahab, S. A., Latiff, A. S., Osman, S. I., Zawawi, N. F., \& Fazal, S. A. (2018). Sustainable Growth in SMEs: A Review from the Malaysian Perspective. J. Mgmt. \& Sustainability, 8,43

Kalpande, S. D., Gupta, R. C., \& Dandekar, M. D. (2010). A SWOT analysis of small and medium scale enterprises implementing total quality management. International Journal of Business, Management, and Social Sciences, 1(1), 59-64.

National SME Development Council (NSDC). (2018). 'A Connected World: Digitalizing SMEs' (SMEs Annual Report 2017/2018, YAB Prime Minister Message. Retrieved: http://www.smecorp.gov.my/index.php/en/laporan-tahunan/3342-laporan-tahunan-pks-2017-18

Department of Statistics, Malaysia (DOSM). (2018). 'The Initial Assessment of the Sustainable Development Goals Indicators for Malaysia 2018' ISBN: 978-967-2000-57-0, Published and printed by the Department of Statistics, Malaysia. Retrieved: https://www.dosm.gov.my

Central Bank of Malaysia. (2013). Circular on New Definition of Small and Medium Enterprises (SMEs), Manufacturing Definition. Retrieved: http://www.bnm.gov.my/files/2013/sme_cir_028 1 new.pdf

SME Corporation Malaysia. (2013). Guideline For New SME Definition. Updated 2016. Retrieved: http://www.smecorp.gov.my

Ministry of International Trade and Industry Malaysia (MITI). (2017). MITI REPORT 2017, ISSN 0128-7524 June 2018, published and printed by the Ministry of International Trade and Industry Malaysia.

Malaysia Productivity Corporation (MPC). (2010). 'Sustainable Development Initiatives in Malaysia', ISBN 978-983-2025-72-6. Retrieved: http://www.mpc.gov.my/wpcontent/uploads/2016/04/Sustainable-Development-Initiatives-In-Malaysia.pdf

Department of Statistics, Malaysia (DOSM). (2018). Press Release, The Performance of State's Economy, 2017, Retrieved: https://www.dosm.gov.my

Ministry of International Trade and Industry Malaysia (MITI), Economics Census 2016 (2017), MITI REPORT 2017. Retrieved:

https://www.miti.gov.my/miti/resources/MITI\%20Report/MITI\%20REPORT\%202017.pdf

Behzad, N., Ahmad, R., Saied, P., Elmira, S., \& Bin, M. M. (2011). Challenges of solid waste management in Malaysia. Research Journal of Chemistry and Environment, 15(2), $597-600$

International Organization for Standardization ISO Central Secretariat Chemin de Blandonnet 8 Case Postale $401 \mathrm{CH}-1214$ Vernier, Geneva Switzerland iso.org ๑ ISO, 2015 All rights reserved ISBN 978-92-67-10650-2

Costa, F., Lispi, L., Staudacher, A. P., Rossini, M., Kundu, K., \& Cifone, F. D. (2019). How to foster Sustainable Continuous Improvement: A cause-effect relations map of Lean soft practices. Operations Research Perspectives, 6, 100091.

Rohac, T., \& Januska, M. (2015). Value stream mapping demonstration on the real case study. Procedia Engineering, 100, 520-529.

Singh, J., \& Singh, H. (2012). Continuous improvement approach: state-of-art review and future implications. International Journal of Lean Six Sigma. 